\title{
LEITURA FÍLMICA: UMA ANÁLISE DISCURSIVA DOS EFEITOS DE SENTIDO DE TEMAS ABORDADOS EM DESENHO ANIMADO DA TURMA DA MÔNICA
}

Sandro Braga

\section{RESUMO}

Apresentamos uma discussão acerca da leitura em sala de aula. Entendemos a leitura como uma prática para além da materialidade da escrita. A partir do escopo da Análise do Discurso de inspiração francesa, investimos na perspectiva de que ler é interagir. Para isso, é necessário saber ler o mundo, interpretá-lo e, por fim, reescrevê-lo. Assim, propomos a leitura de filmes da Turma da Mônica como instrumentalização para outros processos de leitura do mundo atual, que é permeado de imagem e som. Nosso foco está na formação de leitores críticos, capazes de percorrer as tramas discursivas que levam um texto a produzir sentido.

PALAVRAS-CHAVE: Leitura audiovisual; Interpretação; Turma da Mônica.

\section{Introdução (ou era uma vez)}

\footnotetext{
presentamos, neste artigo, parte de uma pesquisa em andamento sobre gestos de leitura em sala de aula. Entendemos a leitura, de forma ampla, como uma prática para além da decodificação das palavras. Assim, é necessário pensarmos também nos processos de leitura que envolvam a linguagem não verbal. Particularmente, neste trabalho, focaremos o cruzamento do verbal com o nâo verbal na produçáo de narrativas de texto cinético.
} 
Partindo do pressuposto de que ler é interagir, dizemos que se faz mister saber ler o mundo, interpretá-lo e, por fim, reescrevê-lo. A partir do exposto, justificamos nosso trabalho tendo, em vista a necessidade da formaçâo de leitores críticos, capazes de percorrer as tramas discursivas que levam um texto a produzir sentido. E mais, leitores que compreendam os caminhos que levam a um sentido dentro da gama de possibilidades semânticas que um texto pode abarcar.

Nossa compreensão de texto também é açambarcada em sua amplitude, assim o compreendemos não apenas no registro da linguagem verbal, mas como defende Barthes (1988, p. 70)², "efeito de escritas múltiplas, oriundas de várias culturas e que entram umas com as outras em diálogo".

Levando em consideraçáo a ampliação da concepção de texto e de leitura, propomos a leitura audiovisual de filmes da Turma da Mônica como instrumentalizaçáo para outros processos de leitura do mundo atual que é permeado de imagem e som. Compreendemos que as mensagens audiovisuais mostram, dizem e informam a respeito do mundo em que vivemos, além é claro, de construírem uma determinada visão de mundo.

Instrumentalizar o leitor para os processos de formulação de sentido pode auxiliá-lo na análise e na formulação de seu próprio discurso. Desse modo, a apreciação audiovisual pode possibilitar ao interlocutor dessa materialidade textual entender a natureza dessa linguagem, sobretudo transformá-lo em um receptor mais crítico, capaz de reconhecer e produzir sentidos.

Para alcançar nosso propósito, filiamos nossa pesquisa dentro do quadro teórico da Análise de Discurso (AD) de vertente francesa. Como explica Eni Orlandi, no Brasil, uma das precursoras teóricas da área, a Análise de Discurso:

[...] como seu próprio nome indica, não trata da língua, não trata da gramática, embora todas essas coisas lhe interessem. Ela trata do discurso. E a palavra discurso, etimologicamente, tem em si a ideia de curso, de percurso, de correr por, de movimento. O discurso é assim a palavra em movimento,

1 BARTHES, R. O rumor da língua. Tradução Mario Laranjeira. São Paulo: Brasiliense, 1988. p. 70. 
prática de linguagem: com o estudo do discurso observa-se o homem falando. (ORLANDI, 2001, p. 15)².

A forma como a $\mathrm{AD}$ concebe a linguagem, os textos e, consequentemente, o discurso é de extrema importância para que as práticas de leitura sejam discutidas e ampliadas no contexto escolar. A opacidade, a historicidade, a exterioridade que reveste e perpassa a linguagem, portanto, os processos de produção e leitura de textos, (e que são aspectos levados em conta pela Análise de Discurso) são alguns dos elementos que servirão como base para nossa análise. Esse fator é fundamental, pois desconstrói a ideia de que ao enunciar conseguimos expressar exatamente o que queremos, e de que qualquer texto pode ser lido do mesmo modo por qualquer leitor que domine o código. Ler, numa perspectiva discursiva, vai além da mera ativação da cognição no reconhecimento de repertório prévio para estímulo de aquisição de novas informações para ampliação do conhecimento enciclopédico. Uma concepção discursiva de leitura considera essa mobilização, porém, soma a isso as condiçóes de produção de textos e de leituras. E, nesse processo, entra em cena a relação entre sujeitos (autor e leitor), sendo essa relação mediada pelo inconsciente e pela ideologia que constituem esses sujeitos.

Chamamos a atenção para a necessidade de produzir conhecimento sobre o desenvolvimento da linguagem audiovisual, levando em consideração que esse tipo de produção cultural e industrial está fortemente arraigado aos processos de comunicação de massa. Outro ponto importante a destacar é que a pesquisa, voltada para a formação do leitor de produção fílmica pode corroborar também na leitura de outras plasticidades como a fotografia e as artes plásticas, despertando o senso crítico e também o reconhecimento da natureza da linguagem e de seus elementos técnicos, criativos e estéticos.

Consoante a necessidade de formação de leitores dos mais variados tipo de textualidades, cabe perguntar de que maneira a escola pode proporcionar ao aluno das séries inicias ferramentas para além da decodificação do texto escrito? Ou ainda, como o processo de ensino-aprendizagem pode fomentar a leitura de textos audiovisuais? E, por fim, como a leitura desenvolvida sob a

2 ORLANDI, E. Análise de discurso: princípios e procedimentos. 3.ed. Campinas: Pontes, 2001. p. 15. 
perspectiva de uma atividade de interpretação pode levar o aluno à compreensão da pluralidade de sentidos que um texto pode conter?

Mediante a configuração deste artigo, propomos como objetivo analisar, a partir de narrativas fílmicas da Turma da Mônica, os efeitos de sentido evocados dos discursos acerca dos temas abordados no texto cinético, uma vez que pensar na formação de leitores é pensar como o próprio sujeito é constituído na sociedade em que atua. E, ainda, é promover o trabalho com textos, a fim de se evidenciar a opacidade da linguagem, apontando como os sentidos circulam em uma sociedade, marcados sempre por filiaçóes históricas.

Metodologicamente, a pesquisa delineia-se como bibliográfica, que investe nos percursos do trabalho da leitura como processo de interpretação e produção de sentido(s). ${ }^{3}$

\section{Percurso teórico (ou nas trilhas do sentido)}

Ancoramo-nos em pressupostos da Análise do Discurso de vertente francesa, sobretudo nas formulaçóes pecheteanas que definem fatores considerados cruciais no processo de leitura - a (re)construção de um texto -, desencadeadores de sentidos, além do texto em si. Esses sentidos, emergentes de gestos de leitura, para a $\mathrm{AD}$, são resultados das condiçóes de produção que envolvem os contornos da leitura. Dito de outro modo, são as condiçôes de produção que definem o que se lê, o modo de leitura e como se lê um determinado texto. Leituras possíveis numa época podem não ser em outras, e vice-versa. Ou seja, todo texto tem sua história; portanto, sua relação de significação vincula-se às possibilidades de dizer e de não dizer do seu tempo. Desse modo, não se pode conceber, sob essa perspectiva, que, hodiernamente, o ensino de leitura na escola ainda se prenda na decodificação e na busca de uma única interpretação possível.

Outro aspecto importante a se considerar a partir de Pêcheux $(1995[1975])^{4}$ é a relação do controle do sentido no ato de enunciar. Para dar conta des-

3 Um próximo passo da pesquisa prevê a aplicação dessa primeira etapa em uma pesquisa-ação e etnográfica, sendo o corpus constituído por gravaçóes de entrevistas semiestruturadas realizadas com os sujeitos (professores e alunos do ensino fundamental) em uma turma de $4^{\mathrm{o}}$ ano de uma escola, pertencente à rede pública, antes e após a assistência fílmica.

4 PÊCHEUX. M. Semântica e discurso: uma crítica à afirmação do óbvio. Tradução Eni Orlandi. Campina: Unicamp, 1995 [1975]. p. 173. 
sa questão, o autor propóe a formulação da teoria dos esquecimentos (um e dois). No esquecimento número um, o sujeito enuncia sob a ilusão de que é dono de seu dizer, criador absoluto dele, e apaga tudo que remete ao exterior de sua formação discursiva. Já no esquecimento número dois, o sujeito, ao enunciar, possui a ilusão de que sua formulação contém apenas um sentido, ou seja, ele acredita controlar o sentido do seu dizer, e de que tudo que ele diz será captado pelo interlocutor. Pêcheux enquadra o primeiro esquecimento como sendo ideológico e o segundo como sendo da ordem enunciativa.

Como já sinalizado, a atividade de leitura, na perspectiva discursiva, considera os diferentes tipos de discurso, produto da história de leitura de textos e, além de levar em conta, também, a própria história de leitura do leitor (ORLANDI, 1996) ${ }^{5}$. Sobre esse aspecto, cabe retomar duas formas distintas que se cristalizam ou se sobrepóem na formação do leitor: a leitura parafrástica, que repete o dizer do autor; e/ou a leitura polissêmica, aquela que consiste na atribuição de múltiplos sentidos ao texto. Orlandi (1996, p. 38) ${ }^{6}$ destaca que essa perspectiva discursiva de leitura procura observar o processo de sua produção e, logo, da sua significação, "o leitor não apreende meramente um sentido que está lá; o leitor atribui sentidos ao texto.”. E completa afirmando que a leitura é produzida e, portanto, pode-se dizer que é o momento crítico de constituição de um texto. $\mathrm{O}$ que explica por que as leituras, numa linha discursiva, não são idênticas, tendo em vista que a linguagem, como processo comunicativo, é histórica e social. Essa perspectiva se opõe a uma visão reducionista de leitura como mera decodificação que tem como propósito a apreensão de um sentido/informação dado como único pelo texto (ORLANDI, 1996) ${ }^{7}$.

$\mathrm{Na}$ produção de significação de um texto, temos de um lado, os sentidos já estabelecidos em outros lugares e que afetam sobremaneira a linguagem no momento da produção de enunciados. No entanto, as condiçóes de produção da leitura também podem fazer emergir novos sentidos, pois cada leitor é constituído numa determinada posição de sujeito e, por isso, podemos dizer é afetado por formaçóes discursivas que o levam a um modo ou outro de interação com a materialidade textual, estabelecendo relaçóes com a memória

5 ORLANDI, E. Discurso e leitura. 3 ed. Campinas-SP: Editora da Unicamp, 1996. p. 41.

6 ORLANDI, E. Discurso e leitura. 3 ed. Campinas-SP: Editora da Unicamp, 1996. p. 38.

7 ORLANDI, E. Discurso e leitura. 3 ed. Campinas-SP: Editora da Unicamp, 1996. p. 38. 
discursiva desses dizeres. Ou seja, os interdiscursos podem ser mobilizados diferentemente a cada nova enunciação, e, assim, um sentido outro pode ser atribuído a um mesmo anunciado. Nas palavras de Orlandi, (1996, p. $87)^{8}$ a "possibilidade de se ler um mesmo texto de várias maneiras" remete àquilo que, em princípio, seria singular à sua pluralidade e, acrescentamos, é isso que dá à leitura uma plasticidade cambiante; o sentido sempre pode ser outro.

Um dos problemas que percebemos inerente às práticas de leitura, sobretudo no ensino fundamental, é que o professor porta-se como mediador entre o texto do autor e o sentido dado pelo aluno. E mais, essa mediação ou é pautada por atividades de compreensão do texto lido ou pelo sentido ao texto já atribuído pelo "leitor-professsor". Não se abre espaço para novos sentidos que poderiam ser postulados pelos leitores-alunos.

Nesse ponto, cabe lembrar também a formulação de Orlandi (1996) ${ }^{9}$ acerca do discurso pedagógico. Para ela, o pedagógico é composto por três outros funcionamentos discursivos: o discurso lúdico, o discurso autoritário e o discurso polêmico. A autora explica que o primeiro manifesta-se pela abertura total do sentido. A esse modo de mobilizar o pedagógico, Orlandi critica, pois, conforme argumenta, abre possibilidade para o nonsense, fomentando o "vale tudo" do dizer, sem qualquer tipo de controle do sentido. $\mathrm{O}$ segundo, que Orlandi aponta como sendo o predominante na escola, é identificado como autoritário, pois a única explicação para o sentido está no sintagma "é porque é". Esse discurso mobiliza o sentido a partir da leitura parafrástica que busca repetir o dizer do discurso científico. Desse modo, a escola se apropria do discurso da ciência como um dizer inquestionável, diríamos contrário ao próprio princípio do fazer ciência, que se propóe a novas descobertas mesmo que isso, muitas vezes, ponha em xeque conhecimentos postulados anteriormente. Por fim, ao caracterizar o funcionamento do discurso polêmico - com pouco espaço no ambiente escolar ainda -, Orlandi trata da abertura controlada do sentido. Nesse modo de funcionamento do discurso pedagógico, haveria maior possibilidade para o aluno juntamente com o professor trabalharem sob gestos

8 ORLANDI, E. Discurso e leitura. 3 ed. Campinas-SP: Editora da Unicamp, 1996. p. 87

9 ORLANDI, E. A linguagem e seu funcionamento: as formas de discurso. 4. ed. Campinas: Pontes, 1996. p. 29. 
de interpretação, ou seja, investirem nos caminhos de sentidos que levam um texto a produzir sentido. A perífrase "abertura controlada do sentido" aponta para a pluralidade de leituras e do sentido, no entanto, mostra também que há um limite para o sentido. Para o sentido fazer sentido é preciso que possa ser retomada a trilha da significação. Destacamos a importância de a escola fazer menos uso do discurso autoritário e se apropriar mais de práticas do discurso polêmico, pois, assim, o aluno passaria a ser menos reprodutor/repetidor, inscrevendo-se numa postura crítica. E, dessa maneira, a escola cumpriria de forma mais efetiva sua função de formação de cidadãos.

\section{Proposta analítica (ou pensando melhor)}

A título de contextualização da temática a ser analisada, trazemos uma descrição dos primeiros fotogramas da cena narrativa fílmica de Era uma vez (Turma da Mônica - Maurício de Souza), bem como fragmentos do diálogo dos personagens.

$\mathrm{O}$ primeiro quadro mostra a casa em que se encontram os personagens (Cascão, Mônica, Cebolinha e Do Contra) num dia de chuva. Na sequência, surge Cascão olhando a chuva através da janela, e inicia o diálogo.

Cascão: Porcaria não vai dar pra jogar bola hoje.

Cebolinha: Sossega vai Cascão.

[Cascão faz cara de emburrado e joga a bola para o chão.]

Mônica: Ah, para com isso vai Cascão. Futebol é uma brincadeira violenta. Todo mundo se machuca quando joga.

[O tom da voz da Mônica surge mais suave que de costume em outras histórias, contrastando com o de Cascão que entoa uma voz mais grossa que de costume também.]

Cascão: Ih.

Mônica: Por que não brincamos de "Era uma Vez"?

Cascão: Ora essa porque nós somos homens; tá legal! Esse negócio de "Era uma Vez" é coisa de maricas.

Mônica: Sério?!

Cascão: O meu negócio é futebol. Saca? É tapa na orelha e poeira no pé. Lá, lá, lá, lá. 
Mônica: Tubo bem, pode sair e jogar. [Entrega a bola de futebol que está em suas mãos para o Cascão.]

[O fotograma seguinte registra um relâmpago e um estrondo de trovão.]

Cascão: [Devolvendo a bola para Mônica] Ai, falando a verdade esse negócio de machismo é uma grande besteira, hâ!

Cebolinha: E como é que se blinca disso?

Mônica: Um de nós conta uma história e os outros continuam de onde ela parou.

A trama narrativa surge trazendo no bojo a problemática da temática dos atributos inerentes aos gêneros. Num primeiro momento, as características correspondentes aos gêneros masculino e feminino emergem, evidenciando um certo discurso cristalizado socialmente sobre o que é ser menino. Esse lugar da subjetividade masculina é marcado pela oposição ao espaço do feminino que, na cena em questão, também contribui para definir o que é ser menina. Nesse espaço enunciativo, esse efeito de sentido é possível, e diríamos mais, é proposto, fazendo emergir sentidos já imbuídos nessa rede semântica da significação pela diferença. Dito de outro modo, esse sentido só é possível porque já fez sentido antes.

A questão é delineada pelos papéis a serem desempenhados em atividades lúdicas por meninos e meninas, mas não apenas isso. Uma série de outros fatores correspondentes aos gêneros vai surgindo no texto de modo a evidenciar as diferenças que marcam cada sujeito. $\mathrm{Na}$ sequência, destacamos alguns elementos que reforçarão os lugares de composição de subjetividades masculinas, contrapondo-se à feminina.

Primeiramente, apontamos, já nos primeiros fotogramas de abertura da narrativa, a composição figurativa dos espaços, bem como de seus ocupantes. Todos os personagens encontram-se dentro de casa, no entanto, Cascão, o primeiro personagem a compor cena, está voltado para fora, alheio ao ambiente interno da casa, com o olhar fixo para o jardim. Ele só está ocupando aquele espaço em virtude da forte chuva, sua reclamação consiste justamente porque não pode estar na rua jogando bola. Destacamos aqui a rua - o externo -, aderente a um gênero (masculino), e a casa - o interior -, pertencente a outro gênero (feminino). 
Na mesma lógica da oposição ao que é da ordem do masculino e do feminino, registramos a entrada da linguagem verbal na trama. Nossa notação recai sobre os itens lexicais selecionados na construção dos diálogos inerentes aos interlocutores (meninos e menina). O primeiro enunciado é pronunciado por Cascão. E o interessante é atentar para o primeiro vocábulo de sua fala: "porcaria". No contexto, o termo surge como protesto, uma queixa, por seu impedimento de praticar a atividade futebolística. Nesse ponto, cabe uma observação: o personagem é caracterizado por ser um garoto que não gosta de tomar banho; portanto, qualquer contato com a água deve ser evitado. Assim, o uso de "porcaria" pode remeter à própria personificação do personagem, funcionando menos como uma metáfora e mais com uma metonímia, ou seja, a sujidade, a imundice é constitutiva desse próprio sujeito. Aliado a isso, cabe em nossa análise remeter o léxico "porcaria" ao universo constituinte da subjetividade masculina. O homem é o ser que se submete às intempéries, às impurezas da rua, já à mulher cabe a limpeza e a manutenção do lado interno da casa. Disso, ainda podemos aludir à mulher imaculada, e aqui o adjetivo da palavra 'pureza' serviria aos sentidos denotativo e conotativo, enquanto o homem estaria inerente aos riscos e às contaminações mundanas. Usando o mesmo recurso da concepção de assepsia versus contaminação, no transcorrer da narraçáo, surge uma cena em que o personagem Do Contra pergunta se antes de iniciar a brincadeira dá tempo de ele ir ao banheiro; no entanto, antes de sair da sala não consegue conter a saída de gases e contamina todo ambiente, causando desagrado aos demais integrantes do quadro, uma atitude, ao que nos parece, possível apenas a um personagem masculino.

Outro elemento que corrobora a delimitaçấo dos universos de cada gênero pode ser observado no registro acentuado da tonicidade das vozes dos primeiros personagens na instauração do diálogo (Cascão e Mônica). No recorte que trouxemos da narrativa, chamamos atenção, entre colchetes, para a tonicidade da voz da Mônica na história em questáo. Como assinalado anteriormente, o tom da voz de Mônica, nessa narrativa, surge com uma frequência mais alta que de costume e produz uma emissão sonora mais aguda, caracterizando-a ainda mais feminina. O afinamento e a macieza da voz da única personagem (menina) aparecem na composição da cena fílmica como elementos que constituem o modo de produção de características a esse corpo 
feminino, remetendo-o à ideia de um corpo dócil (FOUCAULT, 1977) ${ }^{10} \mathrm{e}$ delicado. Observamos que essa formulação foucaultiana está implicada nos dispositivos de controle dos corpos. Segundo o autor, "o corpo, do qual se requer que seja dócil até em suas mínimas operações, opõe e mostra as condiçôes de funcionamento próprio a um organismo. O poder disciplinar tem por correlato uma individualidade não só analítica e 'celular', mas também natural e 'orgânica'." (FOUCAULT, 1977, p. 141)11. De forma análoga, mas usando uma estratégia contrária, o modo de produzir a voz do menino Cascáo em uma frequência baixa altera o tom dessa voz masculina para uma pronúncia mais grave que aquela comumente representada em outras narrativas. Não só o tom da voz do Cascão lhe garante atributos rudes; suas atitudes - como lançar e jogar a bola ao chão - asseguram-lhe o lugar da força e da brutalidade.

Procuramos destacar até este ponto como o autor problematiza as relaçóes de gêneros intrínsecas - discursivamente - ao universo de meninos e meninas, de modo a evidenciar comportamentos femininos e masculinos aderentes a um discurso que socialmente produz evidências naturalizadas e naturalizantes desses modos de se portar como sujeitos portadores de sexo que atribui papéis de gênero. Na sequência da narrativa, Souza ratifica essa problemática de modo mais evidente e explícito fazendo-a transparecer no próprio diálogo de Cascão: "Ai, falando a verdade, esse negócio de machismo é uma grande besteira, hã!”. Aqui poderíamos questionar se Cascão teria essa atitude não fosse sua resistência em sair na chuva; no entanto, não nos prenderemos a esse estímulo do personagem. O que se observa é que, de algum modo, ou, por algum motivo, Souza e Cascão ascendem a um discurso que procura desconstruir outro discurso, ou seja, aquele cristalizado e que evidencia marcadamente a diferença de comportamento entre os gêneros.

Assim, na sequência da narrativa, pode-se observar a inserção dos meninos na atividade lúdica proposta pela personagem Mônica. Cabe uma nota que, a partir desse momento da história, circunscrevem-se no plano do texto cinético duas narrativas entrecortadas, mas que se sobrepóem. A primeira é composta retratando os personagens tal como são constituídos, por caracte-

10 FOUCAULT, M. Vigiar e punir. Tradução Lígia M. Pondé Vassalto. Petrópolis: Vozes, 1977. p. 141.

11 Idem nota 10. 
rísticas já conhecidas da composição figurativa dos personagens da Turma da Mônica. A segunda é constituída por uma nova caracterização atribuída aos personagens que adentrarão a narrativa "Era uma vez". Dito de outro modo, ora são os personagens Mônica e Cebolinha narrando a história, ora esses personagens assumem a identidade dos protagonistas da narrativa que formulam. Esse jogo de duplicidade é marcado pela caracterização imagética corresponde à oposição identitária que eles assumem. Observa-se ainda que no jogo que os personagens da Turma da Mônica vão propondo há uma mescla de características dos atores que compóem uma e outra narrativa; mistura essa que causa certa confusão e estranhamento ao que seria da ordem da realidade vivida no primeiro plano e da ficcionalidade sugerida no segundo plano.

Cebolinha se propóe a iniciar o jogo narrativo de "Era uma vez".

Cebolinha: Ela uma vez um cavaleilo elante, bonito e chalmoso em busca de foltuna e liqueza, cavalgando numa lagaltixa gigante, velde e amnésica.

[...]

Ele cavalgou até uma pequena vila e chegando lá encontlou uma camponesa. Ela ela baixinha, dentuça e muito feia.

[...]

Aí o cavaleilo bonitão disse: oh feia e dentuça camponesa, podelia me tlazer um copo de chocolate quente e bolachas?

Nisso, o despertador marca o término do tempo de Cebolinha. Mônica toma o rumo da narrativa:

Mônica: Então, ela respondeu: Chocolate quente eu não tenho, mas quanto às bolachas .... [parte para cima de Cebolinha, surrando-o.]

Na sequência, Mônica reformula as características da personagem:

Mônica: Na verdade, a menina era uma linda e maravilhosa princesa. Olhou bem para o cavaleiro e viu que ele não era de se jogar fora. E resolveu levá-lo para o seu castelo particular. [A 
princesa (Mônica) pega o cavaleiro (Cebolinha) nos braços e carrega-o em direção ao castelo. $\mathrm{O}$ cavaleiro se debatendo nos braços da princesa grita] "Parem a histólia, parem a histólia, parem a histólia, parem a histólia, parem a histólia, parem a histólia". [Mônica segue narrando.] Chegando ao castelo, os preparativos já tinha sido feitos.

Cebolinha: Que plepalativos?

Mônica: Do casamento, oras. [Cebolinha tenta fugir, mas Mônica o segura.]

Como já pontuamos, num primeiro momento, Souza faz emergir em seu texto cinematográfico a problemática tangente às questôes de gênero. Para isso, marca, a partir de discursos sedimentos, o que seria pertencente à correspondência de posiçóes subjetivas a meninos e meninas. Na tentativa de propor uma alteração a essa estabilização, Souza procura desmanchar, borrar as fronteiras entre esses lugares. Mônica é uma menina forte que enfrenta e bate nos meninos; Cascão tem medo de água. No entanto, como pontuamos, mais detalhadamente na seção teórica, o sentido sempre pode ser outro. Além disso, é uma ilusão pensarmos que controlamos os efeitos de sentido de nosso dizer, ou seja, que, ao enunciar, a significação só pode ser atrelada a um campo de filiação semântica. Retomamos essa formulação para pontuar como os sentidos nos escapam. Souza inverte a pertença aos papéis de gênero ao fazer com que os personagens masculinos deixem de jogar bola na rua - "uma brincadeira violenta" - para inseri-los no universo do interior da casa para contar histórias. Atentamos para o nome da brincadeira: "Era uma vez". Este sintagma aponta para a forma prototípica de introdução de histórias do gênero contos de fada. Narrativas essas atreladas ao universo da mulher que acredita e espera ser protagonista de uma história com final feliz de cunho amoroso e romântico. Portanto, um menino que se insere no universo da brincadeira "Era uma vez" colocaria em suspenso sua condição de masculinidade calcada nos princípios discursivos da virilidade; por isso, a afirmação de que esse tipo de brincadeira "é coisa de maricas". No entanto, no decorrer da trama - sobretudo aquela que surge em segundo plano -, parece escapar do autor sentidos à narrativa que acabam por corroborar atitudes e comportamentos cristalizados nos discursos constitutivos das posiçóes do que é ser homem e mulher em nossa sociedade. 
Desse modo, esses sentidos acabam, de algum modo, reforçando o discurso da diferença entre homens e mulheres; ou seja, o que são coisas (atitudes, comportamento, atributos, desejos...) de homem e coisas de mulher, que o próprio texto pretendia desconstruir.

Pontualmente, observamos que o plano da segunda narrativa continua a marcar a composição inicial da primeira narrativa: coisas de meninos (portanto, de homens) e coisas de meninas (portanto, de mulheres). A narrativa construída pelos personagens em "Era uma vez" reforça de ideia de dentro e de fora de casa. O cavaleiro errante é um guerreiro que anda pelo mundo em busca de fortuna e riqueza. Ao chegar numa pequena vila, encontra uma camponesa, uma mulher que não conhece o mundo. $\mathrm{O}$ cavaleiro a interpela na busca de serviços domésticos: chocolate quente e bolachas. Quando a narrativa ganha o foco de uma narradora - fato que poderia minimizar a diferença - não o faz. Toda a sequência da reformulação da narrativa - proposta por Mônica - é para evidenciar o desejo feminino do casamento e do amor romântico. Ela leva o príncipe para dentro de seu castelo. Seu sonho é formar uma família. No entanto, no auge da cena do casamento, em que Anjinho pronuncia: "Então, eu os declaro..."; novamente, o relógio soa, indicando o término do tempo de Mônica; Cebolinha vibra: "Yes. Salvo pelo gongo!".

O cavaleiro (Cebolinha) reafirmando seu lugar de homem resiste até as últimas consequências a esse enlace/aprisionamento. Isso é registrado no jogo de trocas - negociação - que mantém com Cascão - aquele que irá dar sequência a construção narrativa. Cebolinha se submete a todas as vontades do narrador, inclusive de ser escudeiro de Cascâo, desde que este lhe salve do casamento. Cascáo aparece na cena também trazendo à tona o lugar cristalizado do masculino, constrói para si a figura de outro cavaleiro "muito mais bonito que o primeiro", apontando a concorrência e disputa entre machos; no entanto, o fato de ser mais bonito não surge numa proposta de disputa pelo amor da princesa. Digno de nota é o fato de que o novo cavaleiro entra em cena montando um camelo, ao que Mônica comenta "se aquele camelo sujar meu tapete", ratificando nossa análise da manutenção da correspondência dos papéis de gênero pertencentes aos espaços e aptidôes. Mônica quer casar, mas nem nesse momento crucial esquece-se dos cuidados com a limpeza do castelo. 
Sobressai, no quadro, o desejo de poder (dominante) por parte Cascão que submete o amigo a seu criado, mesmo que, para isso, tenha de cumprir com a palavra - ao que poderíamos remeter ao chavão "palavra de homem" -, transformando a princesa (Mônica) num "monstrão", também nomeado de "monstrão devorador de maridos".

Ao final da história, instaura-se uma disputa incessante entre Cascão e Cebolinha pelo controle da narrativa,o que culmina com longa luta corporal entre os dois personagens. Mônica retoma a posse da bola e convida Do Contra para jogarem futebol. Ele responde: "Legal Mônica, odeio essas brincadeiras violentas". O desfecho do texto de Souza nos leva a apontar que o autor submete a trama cinética a uma proposta que problematiza dos padróes sociais de comportamentos masculinos e femininos, porém, mesmo inserindo os personagens (meninos) no interior da casa e fazendo-os participar de uma brincadeira proposta por uma menina, nos moldes de brincadeiras típicas de garotas, esses personagens masculinos não produzem inflexóes aos seus modos de subjetivarem-se. Em outras palavras, seus corpos não se dobram ao espaço enunciativo e subjetivo do feminino, e por fim, conseguem transformar a brincadeira de contar histórias em uma "brincadeira violenta", assim como o futebol.

\section{Final (feliz?)}

Nosso percurso, neste artigo, procurou investir na discussão acerca de práticas de leitura no contexto escolar. Práticas essas que se pautem em trabalhar menos os aspectos de codificação e decodificação de língua e passe a focar os processos de produção de sentido(s) dos textos. Desse modo, o entendimento acerca da realização e da materialidade do texto também foi foco de ampliação de concepção. Mais especificamente tratamos dos modos de leitura e processos de significação enquanto efeitos de sentido de textos audiovisuais - tendo como objeto analítico o filme Era uma vez (Turma da Mônica - de Maurício de Souza).

O percurso de nossa análise procurou evidenciar que na tentativa de borrar as fronteiras entre as diferenças dos papéis de gêneros, no tocante aos atributos de meninos e meninas, o autor deixou lhe escapar outros sentidos ao texto cinético. Sentidos estes que corroboraram a diferença entre o que é ser menino (homem) e menina (mulher). Nossa compreensão desse sentido deu-se pela observação de dois momentos constitutivas da narrativa cinematográfica analisada. 
O primeiro marca de forma explícita os lugares espaciais de meninos e meninas. Os meninos configuram-se como pertencentes ao lado de fora da casa e as meninas, ao interior do lar. Atrelado a essa perspectiva, cabe aos primeiros a força para enfrentar os desafios e as contaminações - sujeiras - da vida lá fora e, aos segundos, a proteção e o cuidado - zelo - do lado de dentro. O segundo momento problematiza a diferenças dos atributos de gênero e propõe a desconstrução desse discurso já cristalizado socialmente. No entanto, ao fazer isso, aspectos apontados no primeiro momento (re)surgem na trama, ratificando ainda mais a diferença entres os modos de vida de meninos, que se transformarão em homens, e meninas, protótipos de futuras mulheres.

\section{LECTURA DE PELÍCULA: UN ANÁLISIS DE EFECTOS DISCURSIVOS DE SENTIDO DE TEMAS TRATADOS EN LA HISTORIETA DE LA TURMA DA MÔNICA}

\section{RESUMEN}

Presentamos una discusión de la lectura en el aula. Entendemos la lectura como una práctica más allá de la materialidad de la escritura. A partir del ámbito de análisis del discurso de inspiración francesa, entendimos que leer es interactuar. Para eso, es necesario leer el mundo, interpretarlo y, finalmente, volver a escribirlo. Por lo tanto, proponemos leer películas de la Turma da Mônica como instrumentalización para otros procesos de lectura en el mundo actual que está impregnado de imagen y sonido. Nuestra atención se centra en la formación de lectores críticos, capaces de pasar a través de los intercambios verbales que tienen un texto para producir significado.

PALABRAS CLAVE: lectura audio-visual; interpretación; Turma da Mônica.

Recebido em: 18/03/2013 